\section{Susanna Poppleston}

is a partner with Jeremy Allen

in Poppleston Allen, the high-

profile niche licensing practice,

handling liquor and public

entertainment licensing for

major companies and

individual operators

nationwide.

Keywords:

liquor, licence, public,

entertainment, committee, reform, hours, council

\section{Licensing reforms in England and Wales and their likely impact on business and property}

\author{
Susanna Poppleston
}

Received (in revised form): 26th February, 2001

\begin{abstract}
This paper provides an overview of current licensing, both for liquor and public entertainment. It briefly explains permitted hours, plus the granting and enforcement of the licences by magistrates and local authorities. Moving through small movements in reform, it goes on to deal with the Government's proposals in its White Paper for substantial reforms of the authorities to deal with licensing, the mechanisms of the licences, sanctions, penalties and enforcement. The proposals are set out one by one and examined from the perspective of a lawyer currently actively involved in licensing for major companies and individual operators around the UK.
\end{abstract}

\section{INTRODUCTION}

Businesses which operate in England and Wales with licences for the sale of intoxicating liquor and/or licences for the provision of music and dancing have been able to settle quite comfortably into routines of how to deal with the licensing structure in England and Wales as the legislation is quite elderly.

Liquor licensing is governed by the Licensing Act 1964 and public entertainment licensing is governed inside London by the London Government Act 1963, and in the provinces by the Local Government (Miscellaneous Provisions) Act 1982. Subject to minor amendments over the years, the regimes introduced by this legislation have remained untouched. However, the habits of people seeking leisure activities have changed so dramatically since the Licensing Act 1964 was passed that many English licensing requirements are regarded as antiquated, and the procedures adopted by the different courts around the country have led to large discrepancies, both in technical matters and in the application of policy.

Successive governments have indicated they will reform the legislation, but have found it difficult to do so. The sale of intoxicating liquor is very much bound up in England and Wales with issues of public order, and the police and resident groups have been vociferous in their demands for reciprocal controls if the licensing system is to be freed up. As a result, it was only in 1999 
Licensing Act 1964 who may grant licences to whom and for what hours that we actually saw a white paper put forward by the Government for substantial liquor licensing reform; the paper would also take on board the issues relating to music and dancing.

In addition, developments within central London, in particular Westminster, so far as planning and public entertainment licensing are concerned have raised major issues for the trade. Westminster City Council has adopted a new entertainment licensing policy for entertainment and the provision of late-night refreshment, and is reflecting the same points in its new proposed planning policy. The view the council takes is that certain areas of Westminster are saturated with licensed premises, many operating beyond 1am. This is causing unacceptable disturbance to residents and generally affecting the residential amenity of the area. Accordingly, it will grant no new A3 planning uses (which includes bars and restaurants) for hours beyond lam and will not allow any variations of licences to extend the hours beyond lam or increase the number of persons who may use existing premises. These restrictions have made developers and operators alike very worried about future investment in Westminster, and at today's date (December 2000) nobody can quite see the way forward.

As, hopefully, it will become clear from this paper, the proposed route of reform could put greater power in the hands of local authorities, which may then be tempted to follow the example of Westminster. Unfortunately, Westminster's stated aims at the moment would appear to be diametrically opposite to those stated by the Government in respect of licensing reform.

All this adds up to a great deal of uncertainty for the leisure industry, which is rather against the hopes of the Government in introducing licensing reform for England and Wales.

\section{THE MOVE TO LICENSING REFORM - CURRENT LEGISLATION}

Brief details of the current system will be given so that proposed changes can be assessed in the light of the current practice.

\section{Liquor licensing}

This is governed by the Licensing Act 1964; unless otherwise stated, section numbers quoted in this paper will relate to the 1964 Act. Premises used for the sale of intoxicating liquor have to have the benefit of a justices on-licence, and that licence is held by a named individual. If that individual moves, the licence has to be specifically transferred.

The justices on-licence is granted by licensing committees of magistrates courts to persons who are fit and proper and for premises which are suitably located and properly adapted, allowing normal permitted hours of operation which are generally 11 am to $11 \mathrm{pm}$ on weekdays, with more restricted hours on Sundays and Christmas Day.

It is worthy of note that liquor licensing has traditionally been dealt with by magistrates (lay judges), albeit that they sit as a 


\section{Normal permitted hours and permanent extensions thereto}

\section{Difference in licensing requirements, and attitude to granting licences which developed around the country}

licensing committee. For hundreds of years this has been their jurisdiction, and their attitude to the grant of licences has tended to fluctuate, depending on whether there have been major widespread incidents of public disorder in the country arising from the sale of alcohol, which tends to lead to periods of restrictive grants, or whether public order has improved when the demand for more social drinking areas leads to more numerous grants.

The 1964 Act restricts the sale of intoxicating liquor beyond $11 \mathrm{pm}$ to establishments where the sale of intoxicating liquor is an ancillary feature. Accordingly, premises that operate as restaurants may extend their hours by one hour by use of a supper hour certificate granted under s. 68 of the Act. Restaurants again can have further extensions of their hours to a maximum of $1 \mathrm{am}$ the following morning if they have a supper hour certificate and provide live entertainment.

The most coveted extension to normal permitted hours is the special hours certificate granted under s. 77 of the 1964 Act. Licensed premises qualify for such a certificate if they have a public entertainment licence to allow them to provide music and dancing, and if the premises are structurally adapted and bona fide used for the provision of music and dancing and substantial refreshment to which the sale of intoxicating liquor is ancillary.

There have been hours of arguments before committees up and down the country and in front of the Appeal Court as to the definitions within this section. These are the certificates granted to late-night-operating premises, such as nightclubs and discotheques, but the modern discotheque developed well after 1964 and the requirement that liquor should be ancillary to food and music and dancing is nowadays outmoded and is one of the major points which tourists to this country have difficulty in understanding. Currently, a quiet and relaxed bar with a good-quality clientele who seek to socialise and just have a drink cannot have an extended licence.

There are various facilities within the 1964 Act for extensions for special occasions, but those do not go to the heart of the licensing regime.

\section{Refinements to liquor licensing legislation}

\section{Policies of local licensing committees}

Over the years liquor licensing committees around the country have formed their own policies which relate only to their particular division, covering a very limited area. These have differed, creating huge discrepancies in the way that committees look at licensing applications, and indeed their practical requirements as to how applications are made.

The 1964 Act sets down certain statutory requirements which have to be complied with before a justices on-licence can be granted. One of the most material factors is that plans must be deposited to be looked at by the police, the fire authority, and 
First serious moves to make proposals for amendment and modernisation building control and environmental health departments. This is a sensible requirement to ensure that the premises are properly constructed and safe. However, each committee has had slightly different requirements, including the extent to which those plans needed to be coloured. As a result, a major national operator would have to lodge totally different plans in central London from those which he would lodge in Manchester for exactly the same type of operation.

Different committees developed over the years the doctrine of 'need'. Effectively, committees would state that they would not grant new licences unless a need for such a facility could be demonstrated.

Some committees operated this on a numerical basis. Unless one licence had either been revoked, not renewed or had just disappeared from the commercial map, they would not grant another new licence, no matter how new, up to date and desirable it might be. As a result, many of England's towns and cities had some very tired-looking licensed premises which the public viewed with very critical eyes. They had become far more accustomed to the type of facilities available to them on the Continent and in America and were demanding change. It took considerable pressure on licensing committees to change the attitude, but change it did in the mid-1990s, and this was accelerated by some movement of the Government towards licensing reform.

\section{Report of the Better Regulation Task Force}

This task force was appointed in September 1997 to advise the Government on how to improve the quality of government regulation. It established certain general principles of good regulation which included transparency, accountability, targeting, consistency and proportionality.

Liquor licensing legislation was chosen for the first in-depth review because it appeared to the task force to have unnecessary complexity of legal and administrative procedures.

The task force's report was issued in July 1998 and listed a number of long-term and short-term recommendations for liquor licensing, including the extension of restaurant hours and the amendment of the Sunday Observance Act (an ancient piece of legislation which up until December 2000 prevented payment for entry to premises on Sundays as otherwise the premises became 'disorderly houses'). Its further recommendations went on to include creation of personal and premises licences, flexible opening hours, consistent nationwide conditions to protect the public from nuisance and disorder, and greater controls and sanctions for authorities dealing with liquor licensing. It also, controversially, suggested that liquor licensing should be transferred from magistrates to local authorities.

There were a number of short-term recommendations which could be affected by deregulation rather than primary legislation, 


\section{Music and dancing, and entertainment licences granted by local authorities}

such as amendments concerning Sunday dancing, improving the administrative system for licensing, and concise and transparent local policy documents reflecting national guidance, and the Home Office committed itself in November 1998 to bringing in a number of such matters by way of deregulation.

\section{Public entertainment licensing}

To enable public entertainment to take place in premises, whether it is the provision of music, dancing, or a combination thereof, or entertainment of a like kind, an application must be made to the appropriate local authority for a public entertainment licence.

In London the legislation governing public entertainment licensing is the London Government Act 1963. Outside London, it is governed by the Local Government (Miscellaneous Provisions) Act 1982, introduced to take away the power of grant of public entertainment licences from local licensing committees of magistrates and thereby to separate these licences for the first time from liquor licensing.

The relevant local authority committees have the power to fix conditions relevant to public safety on the face of the licence, which must be complied with by the licensee, and the licence is renewable annually. This compares with liquor licences, which are renewable every three years.

Public entertainment licences, however, can be varied on renewal, having new conditions added or old conditions deleted, and there is the power for committees to vary conditions on application.

Applications are publicly advertised and, if objections are received, the application goes to a hearing before a licensing subcommittee of the local authority. Otherwise, they are generally granted on delegated powers to an officer of the local authority.

\section{Conclusion}

Hence, there are two entirely separate authorities dealing with licensed premises, the licensing committees of magistrates for liquor, and the local authority for public entertainment. In addition, night café licences, or late-night refreshment house licences, depending on the area, are issued by the local authority.

\section{REFORM SO FAR Proposed legislation}

Restaurant hours

This paper has already referred to the fact that premises which have conditions on their justices licence restricting them to trading as restaurants (known as Part IV licences) can apply for a 1am terminal hour if they provide live entertainment. A consultation document on restaurant hours showed that there were few problems anticipated if persons applying for a Part IV licence had an automatic extension of the permitted hours to 12 midnight.

\section{Proposed later hours for dedicated restaurants}




\section{Proposed abolition of 'disorderly houses' under Sunday Observance Act 1780 deregulation, permitting nightclubs to operate for gain on Sundays}

They would then be entitled to apply for a further extension to lam without the need to provide any entertainment. It was considered that 12 midnight was generally uncontroversial for restaurants, but that lam may need consultation in the local area. Of course, such an alteration to licensing hours would need a referral back to any planning restrictions which may affect the terminal hour of the premises.

This deregulation is currently on hold, blocked by the House of Lords, which has indicated that it is unhappy to deal with other matters by way of deregulation at the moment while a major proposal for licensing reform is being considered.

\section{Consultation on Sunday dancing}

Sunday dancing has been restricted in two ways. The Sunday Observance Act 1780 prevented owners and operators of nightclubs making a charge for entry on a Sunday, as payment for dancing would deem the premises 'a disorderly house'.

In addition, special hours certificates, which extend the hours under which alcohol may be sold so long as it is ancillary to music and dancing and food, do not operate on Sundays. The 1964 Licensing Act limits them to Mondays to Saturdays.

The Government committed itself to reform by abolishing the effect of the Sunday Observance Act and by allowing s. 77 certificates to operate on Sundays. This amendment was to be done by way of deregulation, which requires consideration by both Houses of Parliament and their committees to ensure that it is not creating any added burdens but merely removing an unnecessary fetter, in this case on the licensed trade.

The House of Lords became very concerned as to the position of residents, and accordingly the De-Regulation Orders, which dealt with both the Sunday Observance Act and the amended liquor hours, was held up while Home Office officials tried to find a suitable way of overcoming concerns over residents.

After much delay, the De-Regulation Orders were split in half to proceed separately. Accordingly, the effects of the Sunday Observance Act were amended in December 2000 and admission can now be charged to discotheques on Sundays.

However, despite promises that the liquor licensing amendment would also be brought in, it is still awaiting its final approval from the House of Lords. The major outcry is from residents, who in certain areas feel beleaguered, considering that Sunday night is their only proper night of rest. There are therefore additional protections for residents being put into the legislation indicating that the liquor licensing authority must consider the special nature of Sunday before they reach a decision on a special hours certificate, and in any event there would be a latest selling time for alcohol under such a certificate on Sundays of 12.30am, except on the eve of a bank holiday other than Easter. There will also be a general power to exclude Sundays from the special hours certificate on the 


\section{General extensions for new year celebrations}

\section{Good practice guide - the licensing magistrates answer to criticism, with proposals to achieve consistency}

grounds of disturbance caused outside the premises as a result of their use.

Because of problems with this part of the deregulation, the Government has now put the special hours certificate into a separate De-regulation Order for consideration by both Houses of Parliament through their committees. The Government had hoped to bring this in during the course of 2000 , but at the moment it is receding over the horizon.

\section{New Year's Eve}

Millennium licensing hours deregulation proved a success. The Government, however, totally failed to build on that success to get a general agreement for New Year's Eve in time for 2000/01; it is now hoped that the Government will introduce general deregulation in the spring of 2001. At the moment, local committees have lapsed back into their old pre-millennium habits of granting different licensing hours to pubs and clubs around the country, so that one division would allow clubs to trade until $2 \mathrm{am}$ while the neighbouring division would limit them to $12.30 \mathrm{am}$. This does not improve the image of the licensing committees of magistrates in the eyes of the public who, probably rightly, regard this as ridiculous.

\section{Non-legislative changes}

Justices Clerks Society Good Practice Guide

This was the response of licensing justices and their clerks to the criticisms in the Better Regulation Task Force report about their lack of consistency. Effectively, a committee sat down to draft a policy document which could be adopted by magistrates in all licensing divisions across the country. Some committees have added a few local refinements, but generally the policy has been adopted widely across the country and has produced considerable improvement so far as the obtaining of licences is concerned. It has also assisted operators to take a view as to whether they are likely to be granted a licence in certain areas. In particular, the doctrine of need has largely been abandoned, which has effectively cut out trade objections.

The positive effect on the acquisition of premises for licensing purposes has been dramatic because of this clarification of policy. The refusal of licences has to be based on evidence available to the committee, usually to be brought forward by the police, that the grant would give rise to public disorder or disturbance to the local community.

However, the concerns of the police in Westminster that areas have become 'saturated' with licensed premises, leading to disturbance to residents, and comments from other police forces, such as Manchester, that areas have again become saturated, giving rise to increases in statistics relating to disorder, gives warning that there may well be a cut-back in licensing in the near future if the police object because of increases in disturbances. 
The government proposals for reform
One authority to deal with all licensing requirements
Reasons for government preference for local authority
Pubs are trying to reposition themselves into the late-night market, giving people extended drinking time. Customers start their entertainment later than they used to, and expect to stay out later. This is the area of particular difficulty and sensitivity so far as the authorities are concerned.

\section{THE WHITE PAPER}

On 10th April, 2000, Jack Straw, the Home Secretary (Minister of the Interior), published the document Time for Reform: Proposals for the Modernisation of our Licensing Laws. This is a consultation document, and there has been widespread discussion about issues which will only be answered by details omitted from this document but which will have to be incorporated in a draft Bill.

In introducing the reforms, Jack Straw stated:

'We now need modern laws to deal with what is a very old problem. They should allow people to enjoy their leisure as they wish, provided that this does not disturb others. A priority is to make sure that the laws provide effective protection for children. In this White Paper we therefore propose a radically new system which carefully balances rights and responsibilities.

We intend to do this by matching greater freedom and flexibility within sensible boundaries with tough and uncompromising powers for the Police, Courts and Licensing Authorities to deal with any individuals or businesses failing to be socially responsible and abusing these freedoms.'

\section{Summary of proposals}

A single integrated scheme

A single integrated scheme is proposed for licensing premises for the sale of alcohol and the provision of public entertainment and late-night refreshment, including shops, stores and supermarkets as well as pubs, clubs etc. The licensing is to be effected by one locally accountable authority; that authority is to be the local authority and not magistrates.

The white paper sets out what the Government regard as three compelling reasons in favour of giving jurisdiction to the local authority rather than magistrates.

- Accountability - in that the licensing authority should be accountable to local residents whose lives are fundamentally affected by the decisions taken.

- Accessibility - many local residents may be inhibited by court processes and would be more willing to seek to influence decisions if they were in the hands of local councillors.

- Crime and disorder - local authorities now have a leading statutory role in preventing local crime and disorder, and the link between alcohol and crime persuasively argues for them to have a similar lead on licensing. 
The legal age

The legal age for drinking alcohol is to be retained at 18. On balance the Government did not wish to create more regulation than is already in place. It has decided not to go for an age of over 21 as in the USA, where drinking is very strictly controlled.

While there will be strict controls against licensees who sell alcohol to persons who are under 18 , there are no proposals to introduce a national identity card to enable licensees to distinguish persons who may be just under 18 from those who are just over. As this is a nationwide problem for licensees, the lack of such a card on a national basis has caused widespread criticism.

\section{Controls for off-licences}

Off-licence stores are often a cause for concern to authorities in that they all too frequently provide a source of alcohol for under$18 \mathrm{~s}$ and for persons who are going to drink in the street and cause disorder. It is a particular problem if off-licence facilities are close to sports grounds.

Accordingly, the white paper proposes additional controls to deal with these problems. Some of these proposed controls were part of the short-term recommendations of the Better Regulation Task Force:

\section{Problems needing faster consideration than long-term reform}

\footnotetext{
Reducing the burden of transferring licences from person to person
}

- test purchasing — sending in someone under 18 to attempt to purchase alcohol

- prohibition on sales to persons buying on behalf of under-18s

- an offence of permitting sales to under-18s

- an offence for any person to sell or supply to anyone under 18 in any place

- a positive duty on the person selling to be satisfied as to the customer's age

- the power to close off-licences for public order reasons under a temporary closure order effected by a police superintendent.

Garage forecourt convenience stores are permitted to have an offlicence so long as they can show that the bulk of their sales income arises from the sale of non-alcoholic goods. The Government is not inclined to allow this to continue, and is adamantly against offlicences for motorway service stations. This has implications for current business ventures, and also for the development of budget hotels which are springing up not only in locations close to major roads and in town centres, but as part of motorway service stations.

\section{New personal licence}

At the present time the personal and premises licences are rolled together. The idea of an individual personal licence is that once it has been granted to somebody, the person retains it subject to any serious breaches and can therefore take it round the country with $\mathrm{him} /$ her to operate licensed premises. 


\section{How premises would be licensed}

\section{Security and safety conditions proposed}

\section{Grant of new licences in the future}

The personal licence would be for the person responsible for the sale of alcohol at the premises, to ensure awareness of obligations and that he/she is capable of fulfilling those obligations. It would be held by the person running the premises on a day-to-day basis, and is proposed to be issued for a period of ten years. There is a statutory presumption of renewal if there are no problems.

An accredited qualification (such as a training course undergone with a body such as the British Institute of Innkeeping) will give a presumption of the grant of a personal licence in the absence of problems such as criminal convictions. Absence from the trade for five years would invalidate the licence. There would be a system of endorsements for breaches of licensing laws. There would be power to revoke the personal licence if the breach is serious. If there are a number of minor offences the system follows the principle of 'three strikes and you are out' - three breaches and the licensee loses the licence.

The personal licence holder would register with the police and the licensing authority by letter when moving in to take control of premises. At the present time only limited rights of challenge to the police are proposed.

A national database would be required to enable the licensing authorities and the police to keep track of personal licences, endorsements, revocations etc and this, of course, has cost implications which have not yet been addressed.

\section{New premises licence}

The premises licence would authorise the sale and supply of alcohol, the provision of public entertainment (including plays and films) and provision of refreshment throughout the night. All areas will fall under the same regime nationwide.

Not all premises will require the same facilities, and requirements will be set out by the applicant in an operating plan. Applications for premises licences will be supported by the proposed operating plan. This should give a reasonable indication of the limits within which the premises would operate, eg the provision of a discotheque for up to 200 people until 3am on Friday and Saturday nights. It should not go into commercial details, and should be simple and straightforward.

It must include proposals to prevent crime and disorder, such as the provision of door supervisors, closed-circuit television and toughened glass, proposals to ensure public safety, such as the provision of fire exits and a capacity figure, and also arrangements to minimise unreasonable public disturbance, such as acoustic measures.

Need will not be a criterion, and commercial matters will not be taken into account. The licensing decision should not be a re-run of the planning decision. Effectively, there will be a presumption in favour of granting a licence. This grant will be without a hearing if there are no objections which are relevant to licensing 


\section{Abolition of current permitted hours}

\section{Impact on planning}

\section{Protection of residents}

\section{Public order}

considerations from police, fire, local representatives of the Health and Safety Executive, local residents or businesses. The burden of proof would fall on those making the objection.

There will be an end to normal permitted hours as we know them at the moment. Applicants will be able to propose what hours they want and can, if they wish, incorporate into the operating plan proposals for a certain number of special events. The authority may limit proposed closing times to reduce noise and disturbance to residents.

The Government is committed to allowing customers to choose the time when they wish to go home, believing that businesses will then fix their closing time appropriately. Various experiments with the closure of licensed premises has tended to demonstrate that the staggering of closing hours by half an hour or an hour relieves the pressure on services such as taxis and police resources. It is considered that if sufficient time is allowed for the closing of premises then people can leave the premises when they wish. Commercial imperatives, however, may be at odds with the Government's hopes. It is perhaps unrealistic for one pub chain to close its premises at lam while watching their nearest rivals keep their premises open until 1.30am.

A number of other factors will affect the new premises licence:

- Relationship to planning use - there could be a considerable crossover, although this is not intended by the Government. However, the local authority with its different hats will have to consider disturbance to residents - a consideration highlighted by the operation of the Human Rights Act which came fully into force in England at the beginning of October 2000. Residents will be anxious to protect their right to peaceful enjoyment of their homes. The local authorities are going to have to consider whether limitations should be placed on the planning consent or on the licence.

- Duration - the premises licence will be issued for the life of the business, and if there is to be a change in style of the business a new application will be needed. This contrasts with planning. The A3 use covers a quiet restaurant and a very noisy bar with no further application needed.

- The premises licence would be needed for a late night refreshment house, ie food and drink being sold at night, but no personal licence would be required as no alcohol would be on sale.

- Police powers of closure - the Government, to ensure a balance with the increased freedoms in the proposed regime, is considering giving the police enhanced powers to close the premises for 24 hours in the event of public disorder either inside or in the vicinity of the premises which would be resolved by the closure of the premises.

- Liquor sales will be permitted during normal shopping hours for supermarkets, subject to local objection. 


\section{Greater range of sanctions to deal with wider, more flexible licences}

- Children may enter licensed premises unless the licensee opts out in his operating plan and unless the premises licence subsequently forbids it by condition.

\section{Sanctions and punishments}

A greater range of sanctions and punishments will be provided. In addition to prosecution for specific offences, currently licensing authorities may either revoke the licence or not. This is the only option open to them and it is a very draconian punishment, but there is no halfway house.

The proposals would allow an endorsement on either the personal or the premises licence for any breach, and that endorsement will stay on the licence for five years. Three such endorsements in five years would mean the authority considers revocation. There is also a general power to review the licence.

However, since the white paper was published and the consultation process has been completed, the Government is having to consider the general timescales; there is a feeling that they may try to introduce some of the sanctions set out in the white paper in separate legislation. In other words, the enhanced police powers may well be brought in ahead of the more flexible licensing regime. This is of considerable concern to leisure companies. Many enthusiastically embraced the proposals of the white paper on the basis that they would accept the new sanctions and punishments as a quid pro quo for the enhanced licensing. They may now find themselves with the sanction but not the benefits.

\section{General}

The white paper proposes to retain registered clubs and non-profitmaking establishments which are totally private and run their own bars, not under a licence, but under a registration certificate.

The Government is having to pay much more attention to the appeal process, as the major criticism of the white paper is that the transfer of power to the local authorities may prejudice the rights of applicants and residents to a fair hearing under the Human Rights Act. The appeal structure set out in the white paper is based on points of law only, and may well be regarded as unsatisfactory.

The white paper bases a number of its reforms on cost saving, but its authors have not yet put forward any detailed analysis as to how they have reached their conclusions on the costs of the current system, and they have been very vague as to who would be responsible for certain costs - eg the national database of licensees under the new system.

As there are few details in the white paper as to actually how the applications would work it is difficult to estimate how long it would take for a licensing application to be processed. Of the proposals set out in the white paper one appears to be looking at 50 working days as an absolute minimum from the lodging of the application to its disposal without objections. Obviously, businesses would have 
to build this sort of timescale into their proposals when dealing with contracts for acquisition of proposed licensed premises.

As to timescales for bringing in the legislation, these are impossible to calculate. Any government proposals can be interrupted by emergencies within the parliamentary programme, and governments always have an eye to the political main chance. Generally speaking, governments have learnt to their cost that licensing reforms do not always meet with the approval of voters within their constituencies, and they tend to soft pedal as they head towards an election.

\section{CONCLUSION}

In summary, the white paper proposes a flexible licensing system administered by a locally accountable single licensing authority with the ability to impose conditions confined to considerations of preventing crime and disorder, undue nuisance or threats to public safety.

Standard permitted hours would be ended, hours to be indicated on the operating plan, and the premises licence would have relevant conditions including limitations on hours. There is also strong pressure to ensure that safety conditions would include a capacity figure for all premises.

These proposals set out by the Government came before the impact of the Euro 2000 football championship, when it will be remembered that English people abroad did not impress society generally with their behaviour. This 'yob culture' in England and Wales has perhaps encouraged the Government to bring forward its crime and disorder proposals and to think carefully about the checks and balances necessary if it is going to implement a flexible licensing system.

The Government has expressed its view that staggered closing hours are beneficial and that more flexibility enables customers to have a wider choice and better facilities provided for them by operators, which in turn leads to a more civilised society.

This is directly contrary to the view being taken by Westminster City Council at the present time: acting on the views of its local residents, and residents are being encouraged back into central areas, the council has decided that certain parts of Westminster are saturated in licensing terms to the detriment of its residents.

Westminster is anxious to maintain a broad range of uses, but considers that the establishment of megabars - huge licensed premises with A3 use _ has eroded the character of areas which it has marked out as 'stress areas' within the central activity zone. Westminster Council's response to this is to bring in a new licensing policy and a new planning policy which would work hand in hand. This will restrict large A3 uses and in saturated areas will not permit the grant of new licences, but where they are granted will restrict the terminal hour to $1 \mathrm{am}$, the onus being on applicants to 
prove that they will not have any adverse effect on residential amenity.

In other words, Westminster takes the view that by penalising the leisure operator and by cutting back their hours and licences it can solve the problems of noise, degradation of the local environment, increased crime, the quality of life for Westminster residents and their inability to get sleep because of late licences. This is a locally accountable council.

Will other councils follow this example, showing the Government that instead of widening licensing in busy areas, there may well be a narrower approach? For people investing in businesses in these areas the lack of certainty is a major problem, and all eyes are following challenges to the policy which are being pursued through the High Court. However, it seems unlikely that this example is going to deter the Government and we all await an announcement as to when the draft Bill is likely to appear. 